\title{
NEW MENTAL HEALTH AND WELLBEING RESOURCE FORTHE DENTAL TEAM LAUNCHED
}

A UK-wide resource called Wellbeing support for the dental team was launched in January 2021, aimed at all dental team members, including students and non-clinical roles.

Stakeholders from dentistry and beyond came together in February 2020 to discuss the wellbeing of dentists and their teams. Following this a small group of dedicated colleagues collaborated to create this single document.

The guide outlines how to assess your own mental health and wellbeing and provides resources for self-care, including the range of organisations available to support you.

Dental professionals recognise the importance of mental health and wellbeing for their patients. However, they may not always recognise or prioritise their own mental health needs. Stress is common amongst the dental profession and is a key driver of burnout and mental ill health. These problems can affect individuals at any stage of their career

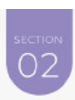

\section{Self-Care for Mental Health and Wellbeing}
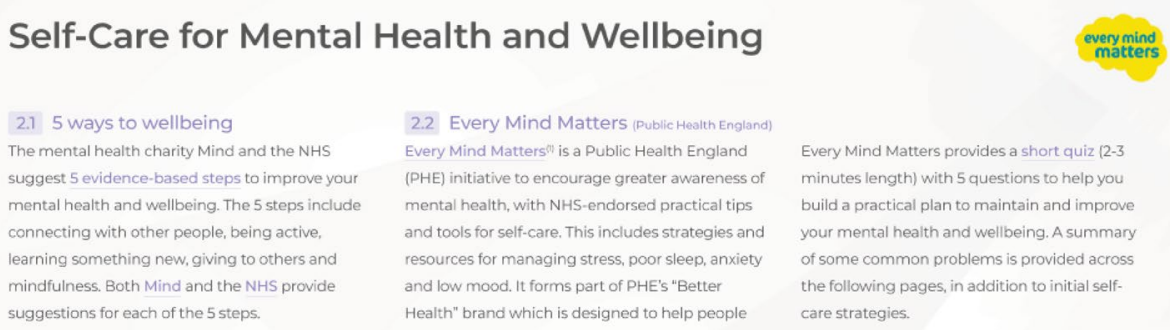

2.2 Every Mind Matters (Public Health Englar (PHE) initivive mentatherin and tools for seltcare. This includes strteges and and tools for self-care. This includes strategies and resources for managing stress, poor sleep, anxiety and low mood. If forms part of PHE's "Better Health" brand which is designed to help people are stategies
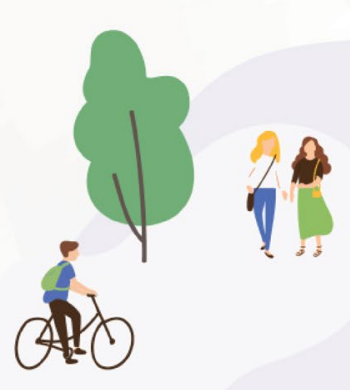

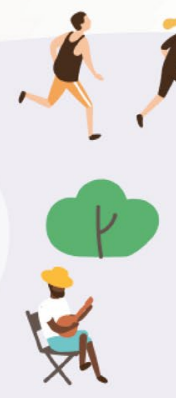

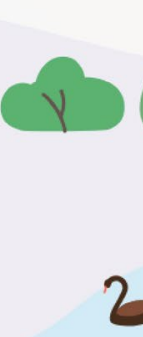
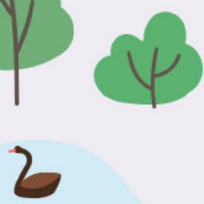

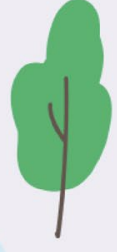

For a variety of reasons, there has traditionally been a reluctance amongst the dental profession to speak about and seek support for their personal problems, including mental health.

It is time to put an end to that. There is strength, not weakness, in asking for help, and to that end, Wellbeing support for the dental team offers simple and practical steps to know where you can find the support you need.

Simply visit https://www.

supportfordentalteams.org to download your free copy.

\section{MOUTH CARE MATTERS E-LEARNING RESOURCES NOW AVAILABLE}

Health Education England e-Learning for Healthcare (HEE e-LfH) has worked in partnership with Health Education England and the Mouth Care Matters team to add Mouth Care Matters, a range of free resources and tools to support health and care teams with knowledge and skills to improve patient oral health, to the e-Learning for Healthcare Hub.

Oral health is an important part of general health and wellbeing. Supporting patients with regular mouth care is a fundamental part of care that has frequently been identified as neglected and needing improvement.

The aim of Mouth Care Matters is to empower staff, through training and education, to identify patients that need help with mouth care and ensure it is delivered in a safe and compassionate way.
Two further resources are also available as part of the Mouth Care Matters programme:

Mini Mouth Care Matters - which aims to empower medical and allied medical healthcare professionals to take ownership of the oral health care of any paediatric in-patient with a hospital stay of more than 24 hours

Mouth Care Matters for Neurodisability - oral health resources to support staff and families caring for people with a

\section{Mouth Care Matters}

neuro-disability.

The Mouth Care Matters programme is freely available to access via the e-Learning for Healthcare Hub.

Please note if you require evidence of learning you will need to register and log in to record your progress and generate a record of completion.

You can learn more about the resources on the Mouth Care Matters programme page: https://www.e-lfh.org.uk/programmes/ mouth-care-matters/. 